\title{
Post-operative Peristomal Skin Complications in Children with Colostomy.
}

\author{
Hanan A. Abd- Elhay ${ }^{1}$, Mohamed A. Osman ${ }^{2}$, Marzoka A. Gadallah ${ }^{3}$ \& Etemad H. Sayed ${ }^{4}$. \\ 1- Assistant lecturer in Pediatric Nursing Department, Faculty of Nursing, Assiut University, Egypt. \\ 2- Professor of General\& Pediatric Surgery, Faculty of Medicine, Assiut University, Egypt. \\ 3- Professor of Pediatric Nursing, Faculty of Nursing, Assiut University, Egypt. \\ 3- Lecturer of Pediatric Nursing, Faculty of Nursing, Assiut University, Egypt.
}

\begin{abstract}
Background: Colostomies are common in pediatric surgical practice. Despite improvements in surgical methods, surgical morbidity and complications rates are still high; Peristomal skin complications affect $18 \%-73 \%$ of children So this study aimed to assess post-operative peristomal skin complications in children with colostomy. Descriptive research design was used in this study. Subjects included 30 children with colostomy from pediatric surgical unit in Assiut University Children Hospital and Pediatric Surgery clinic. Two tools were used for gathering the necessary data which included a structured questionnaire for personal and medical data of children and Ostomy Skin Tool to assess the condition of peristomal skin complications. Results showed that, $(66.7 \%)$ of children had moderate peristomal skin complications at one week from the operation while at the first month; two fifths of children had severe complications. At the second month, (66.7\%) of children had severe peristomal skin complications while majority of them in the third month had severe complications. Conclusion discoloration and erosion complications were the most peristomal skin complications that occurred after colostomy. Therefore, it is recommended that further research should be expanded to include a larger sample, focusing on effects of peristomal skin problems on the child and family.
\end{abstract}

\section{Keywords: Children, Colostomy, Peristomal Skin Complications \& Post-operative.}

\section{Introduction}

Colostomy is a surgically created opening in the abdomen in which a piece of the colon (large intestine) is brought outside the abdominal wall to create a stoma through which digested food passes into an external pouching system (Wound, Ostomy Continence Nurses Society, 2018).

Colostomies are common in pediatric surgical practice and they are often created for the purpose of diverting feces and flatus from distal pathologies in children with high anorectal malformations, Hirschsprung's disease, left colonic atresia, necrotizing entrocolities (NEC), complex pelvic malformations and left colonic traumas in children (Ekwunife et al., 2017).

There are numerous and frequent common complications following construction of large bowel stomas. Despite improvements in surgical methods, surgical morbidity and complication rates are still high. Earlier studies have shown complication rates vary between 6 and $59 \%$ (Formijne et al., 2012). The incidence of complications after colostomy is reported to be between 10\% to $74 \%$ (Bakal et al., 2015). Complications may occur immediately after surgery or late, months or years to appear. Early complications (within first three months) include wound infection, abscess, fistula, retraction, bleeding and small bowel obstruction. Late complications (after first three months) include a para-stomal hernia, prolapse, stricture and severe skin excoriation (Simmi \& John, 2018).

Peristomal skin complications affect $18 \%-73 \%$ of children. Complications range from mild irritation to full thickness ulcerations leading to pain, anxiety, and may significant social isolation related to the pouching system leaks. Common postoperative complications usually occur within the first two weeks of the creation of the stoma. Peristomal skin complications can also present as late complications, months or even years after the initial surgery (Liao \& Qin, 2014 \& Landman, 2016).

Nurse plays an important role in stoma care as preoperative education and counseling, postoperative teaching and emotional support, empty and changing pouching system, describing diet and fluid guidelines, recognizing signs of potential complications, as well monitoring medications, managing gas and odor, teaching patient to seek assistance if experiencing the changes in output, skin and stoma complications. The role of the pediatric nurse also includes discharge planning, outpatient follow up and ongoing rehabilitation care to children and their families (Hockernberry \& Wilson, 2015).

\section{Significance of the study}

Despite colostomy in children is a temporary procedure done for treatment of a non-malignant 
procedure but it has high rate of morbidity and mortality. As a result of lack of facilities and manpower needed to carry out Colostomy. Complications are still occurred in high rate especially peristomal skin complications. Peristomal skin ailment rates can vary from 6\% - 96\% (Simmi \& John, 2018). Implementation of well-established peristomal skin complications treatment techniques must be improved as standard peristomal skin care is not always adequate for preventing peristomal problems which increase child and family anxiety and financial burden to family also it increase hospital cost and stay (Shauq, 2015).

\section{Aim of the Study}

The aim of this study was to assess post-operative peristomal skin complications in children with colostomy.

\section{Research Questions}

*What are the post-operative peristomal skin complications in children with colostomy?

\section{Subjects \& Method \\ Research Design}

Descriptive research design was utilized in this study.

\section{Setting}

This study was conducted in the Pediatric Surgery

Unit and Pediatric Surgery clinic at Assiut University

Children Hospital.

\section{Subjects}

A convenience sampling of 30 children with colostomy in the Pediatric Surgery Unit was included in the study.

Tools

Two tools were used to fulfill this study

Tool (1): A structured interview questionnaire: It included three parts as follows:

$>$ Personal characteristics and medical data of the child include child's age, sex, birth order, and body weight.

$>$ Socio-demographic data of children's mothers as age, occupation, level of education, residence, and number of children in the family.

$>$ Indications of colostomy and problems occurred during hospitalization.

Tool (2): Ostomy Skin Tool: It is a standardized assessment tool developed by (Martins et al., 2013) to help health care professionals in assessing, evaluating and monitoring the condition of peristomal skin reliably and accurately. It consists of standardized descriptions of three characteristics domains of the abnormal peristomal skin (DET): Discoloration (D), Erosion (E) and Tissue overgrowth (T). The Ostomy Skin Tool considers both the percentage of the peristomal skin (area) affected under the adhesive barrier and the severity of the problem within each domain as following:

- The score of area is assigned between 0 and 3 by the size of affected area for example

- Regarding discoloration

- $($ ( Score $)=$ normal skin (absence of any visible change and damage to epidermis) if there is no discoloration then the skin is healthy.

- $(\mathbf{1}$ Score $)=$ if a discoloration is less than $\mathbf{2 5 \%}$, a point of reference is same in erosion and tissue overgrowth).

- $(2$ Score $)=$ a discoloration is between $25 \%$ and $\mathbf{5 0 \%}$, a point of reference is same in erosion and tissue overgrowth).

- $(3$ Score $)=$ if a discoloration is more than $50 \%$, a point of reference is same in erosion and tissue overgrowth).

- The score of severity is assigned between 0 and 2 for DET as follows

1- Severity of discoloration

- $(\mathbf{0}$ Score $)=$ if the skin is normal.

- $(1$ Score $)=$ slight redness or other discoloration of the peristomal skin.

- $(2$ Score) $=$ deep red or highly macerated skin potentially causing further complications.

2- Severity of erosion:

- $(\mathbf{0}$ Score $)=$ no erosion .

- $\quad(1$ Score $)=$ damage to the top layer of the skin (the epidermis).

- $\quad(2$ Score $)=$ damage to dermis causing excessive moisture or bleeding.

3- Severity of tissue overgrowth:

- $(\mathbf{0}$ Score $)=$ no tissue overgrowth .

- $(1$ Score $)=$ tissue overgrowth that interferes with application of the adhesive barrier.

- $(2$ Score $)=$ tissue overgrowth that interferes with application of the adhesive barrier and causes bleeding and / or pain.

- In a situation where a large area of skin with low severity includes a small area with a high severity, the highest severity should always be scored even though the area is small.

- The score of each domain is a range from (0-5). The combined score, or DET score, is in the range from $0-15$ where 0 represents normal skin and 15 the worst combination of severity and extent. Introducing three levels of severity ' $m$ ild' (DET $<4)$, 'moderate' (DET $\geq 4<7)$, and 'severe' (DET $\geq 7)$.

- A pilot study was carried out on $10 \%$ of the sample. The aim of the pilot study was to test the 
clarity and applicability of the tools and to estimate time needed to fulfill each sheet. No modification was done, so children who participated in the pilot study were included in the study sample.

- Ostomy Skin Tool has documented content validity index of 0.990 and demonstrated high equivalence reliability with a satisfactory Interobserver reliability of 0.88 (Harputlu \&Ozsoy, 2017).

- Validity of the tool one was done by five experts in pediatric surgery and nursing field, it was (0.950).

Field of the work

- An official permission was obtained from head of the unit, and also obtained from the manager of Assiut University Children Hospital.

- This study was carried out through a period of nine months from the beginning of January (2018) to the end of September (2018).

- Assessment of personal characteristics data of the child and their mothers was done by the researcher using the first tool.

- The researcher assessed peristomal skin complications in children at first week after operation of colostomy; then one month, two months, and three month according to planned schedule of visits.

- Assessment of the size of the area affected in each of the three domains and score based on the key right of Ostomy Skin Tool (the second tool). Assessment of the severity based on using the photographs as a guide.

\section{Ethical Considerations}

Written informed consent was taken from parents of each child participating in the study and they are secured that data will be confidential and used only for the research purpose. The parents had the right to withdraw from the study at any time during the study without any effect on the care provided for their children.

\section{Statistical analysis}

Data entry and data analysis were done by using SPSS program (Statistical Package for Social Science) version 19. Data were presented as number, percentage, mean and standard deviation. Chi- square test and fisher exact test were used to compare qualitative data. $\mathrm{P}$ value was considered statistically significant when $\mathrm{p}<0.05$.

\section{Results}

Table (1): Percentage distribution of the studied children regarding to their personal data.

\begin{tabular}{|c|c|c|}
\hline \multirow{2}{*}{ Item } & \multicolumn{2}{|c|}{$(n=30)$} \\
\hline & No. & $\%$ \\
\hline \multicolumn{3}{|l|}{ Child's gender } \\
\hline Male & 11 & 36.7 \\
\hline Female & 19 & 63.3 \\
\hline \multicolumn{3}{|l|}{ Child's age } \\
\hline$<1$ year & 3 & 10 \\
\hline $1-<3$ years & 19 & 63.3 \\
\hline $3-<6$ years & 7 & 23.3 \\
\hline$\leq 6$ years & 1 & 3.3 \\
\hline Mean \pm SD & \multicolumn{2}{|c|}{$2.44 \pm 2.41$} \\
\hline \multicolumn{3}{|l|}{ Birth order } \\
\hline First & 11 & 36.7 \\
\hline Second & 13 & 43.3 \\
\hline Third or more & 6 & 20.0 \\
\hline \multicolumn{3}{|l|}{ Residence } \\
\hline Urban & 9 & 30.0 \\
\hline Rural & 21 & 70.0 \\
\hline \multicolumn{3}{|l|}{ Body weight } \\
\hline $1-<11 \mathrm{~kg}$ & 14 & 46.6 \\
\hline $11-<21 \mathrm{~kg}$ & 14 & 46.6 \\
\hline $21-30 \mathrm{~kg}$ & 2 & 6.7 \\
\hline
\end{tabular}


Table (2): Distribution of the studied children related to indications and colostomy problems during hospitalization.

\begin{tabular}{|l|c|c|}
\hline \multicolumn{1}{|c|}{ Item } & No. & \\
\cline { 2 - 3 } & & \\
\hline Indication of colostomy & 18 & \\
\hline High anorectal anomalies & 12 & 60.0 \\
\hline Hirschsprung's disease & & 40.0 \\
\hline Colostomy problems(during hospitalization) & 1 & \\
\hline No problems & 20 & 3.3 \\
\hline Constipation and abdominal distention & 8 & 66.7 \\
\hline Diarrhea & 1 & 26.7 \\
\hline Bleeding & & 3.3 \\
\hline
\end{tabular}

Table (3): Mean score of DET domains according to Ostomy Skin Tool at one week and one month postoperative in the studied children.

\begin{tabular}{|l|c|c|c|}
\hline \multicolumn{1}{|c|}{ DET domains } & One week & One month & P-value \\
\hline Area of discoloration & $2.00 \pm 0.37$ & $2.87 \pm 0.35$ & $0.000^{*}$ \\
\hline Severity of discoloration & $1.53 \pm 0.51$ & $1.93 \pm 0.25$ & $0.0002^{*}$ \\
\hline Area of erosion & $1.97 \pm 0.67$ & $2.57 \pm 0.57$ & $0.0004^{*}$ \\
\hline Severity of erosion & $0.00 \pm 0.00$ & $1.87 \pm 0.35$ & - \\
\hline Area of tissue overgrowth & $0.30 \pm 0.47$ & $0.40 \pm 0.62$ & 0.484 \\
\hline Severity of tissue overgrowth & $0.30 \pm 0.47$ & $0.40 \pm 0.48$ & 0.418 \\
\hline Total score & $7.53 \pm 1.93$ & $9.97 \pm 1.73$ & $0.000^{*}$ \\
\hline
\end{tabular}

* Statistically significant difference $(p<0.01)$

Table (4): Mean score of DET domains according to Ostomy Skin Tool at two months and three months postoperative in the studied children.

\begin{tabular}{|l|c|c|c|}
\hline \multicolumn{1}{|c|}{ DET domains } & Two months & Three months & P-value \\
\hline Area of discoloration & $2.87 \pm 0.35$ & $2.87 \pm 0.35$ & 1.000 \\
\hline Severity of discoloration & $1.87 \pm 0.35$ & $1.93 \pm 0.25$ & 0.447 \\
\hline Area of erosion & $2.60 \pm 0.56$ & $2.60 \pm 0.56$ & 1.000 \\
\hline Severity of erosion & $1.83 \pm 0.38$ & $1.87 \pm 0.35$ & 0.673 \\
\hline Area of tissue overgrowth & $0.40 \pm 0.62$ & $0.40 \pm 0.62$ & 1.000 \\
\hline Severity of tissue overgrowth & $0.33 \pm 0.48$ & $0.33 \pm 0.48$ & 1.000 \\
\hline Total score & $9.90 \pm 1.83$ & $10.00 \pm 1.76$ & 0.829 \\
\hline
\end{tabular}

* Statistically significant difference $(p<0.01)$

Table (5): Ostomy Skin complications percentages in children at one week, one, two and three months postoperative in the studied children.

\begin{tabular}{|l|c|c|c|c|c|c|c|}
\hline \multicolumn{1}{|c|}{$\begin{array}{c}\text { Degree of severity } \\
\text { according to (OST) }\end{array}$} & \multicolumn{2}{c|}{ Mild } & \multicolumn{2}{c|}{ Moderate } & \multicolumn{2}{c|}{ Severe } & P-value \\
\hline Visit & No. & $\%$ & No. & $\%$ & No. & $\%$ & \multirow{2}{*}{0.573} \\
\hline $\begin{array}{l}\text { One week } \\
\text { postoperative }\end{array}$ & 20 & 66.7 & 10 & 33.3 & 0 & 0.0 & $0.000 *$ \\
\hline $\begin{array}{l}\text { One month } \\
\text { postoperative }\end{array}$ & 1 & 3.3 & 17 & 56.7 & 12 & 40.0 & \multirow{2}{*}{$0.000 *$} \\
\hline $\begin{array}{l}\text { two months } \\
\text { postoperative }\end{array}$ & 0 & 0.0 & 10 & 33.3 & 20 & 66.7 & $0.000 *$ \\
\hline $\begin{array}{l}\text { three months } \\
\text { postoperative }\end{array}$ & 0 & 0.0 & 5 & 16.7 & 25 & 83.3 & $0.000 *$ \\
\hline
\end{tabular}

* Statistically significant difference $(p<0.01)$ 
Table (1): Illustrates distribution of the studied children related to personal data. More than half $(63.3 \%)$ of the children were female. Regarding age, $(63.3 \%)$ of them were in $(1-<3$ years) age group with mean age $(2.44 \pm 2.41)$. More than two fifths $(43.3 \%)$ of children were in the second birth order. According to residence, more than two thirds of children came from the rural areas.

Table (2): Indicates distribution of children related to indications and colostomy problems during hospitalization. The high anorectal anomalies were the indication for $60 \%$ of children and Hirschsprung's disease was the indication for $40 \%$ of children. Constipation and abdominal distention were the main problems among $66.7 \%$ of children during hospitalization.

Table (3): Represents that there was a statistical significant differences between children after one week and one month of colostomy according to Ostomy Skin Tool domains as for discoloration area mean score was $(2.00 \pm 0.37$ and $2.87 \pm 0.35)$ respectively with $\mathrm{p}$ value (0.000) and severity of discoloration mean score was $(1.53 \pm 0.51$ and $1.93 \pm$ $0.25)$ in one week and one month of colostomy respectively with $\mathrm{p}$ value (0.0002). While mean score related to area of erosion was $(1.97 \pm 0.67$ and $2.57 \pm 0.57)$ after one week and one month of colostomy respectively with $\mathrm{p}$ value $(0.0004)$.

Table (4):- reveals that there were no statistically significant differences between two and three months postoperative of colostomy in domains of discoloration (area and severity) and erosion (area and severity) or overgrowth (area and severity).

Table (5): represents that more than one half $(66.7 \%)$ of children had mild peristomal skin complications and $(33.3 \%)$ had moderate ones at one week from operation. At the first month, more than one half $(56.7 \%)$ of children had moderate peristomal skin complications and two fifths of children had severe complications compared to $(66.7 \%)$ of children that had severe complications at the second month of operation. The majority $(83.3 \%)$ of children in third month had severe peristomal skin complications.

\section{Discussion}

Colostomy is still an important step in the treatment process in some severe conditions in children that associated with high rates of complications. This study aimed to assess post- operative peristomal skin complications in children with colostomy. Findings of the current study reported that high anorectal malformation was the leading indication for colostomy followed by Hirschsprung's disease as shown in (table 2). This is a similar finding by Zamil et al., (2018) \& Bischoff et al., (2010), they reported that anorectal malformation was a more common indication for colostomy followed by Hirschsprung's disease. Also Naser, (2017), who discussed that colostomy, was the commonest procedure and congenital anorectal anomalies were the most common indications for stoma surgery. This result is also in agreement with the result of Bray \& Sanders, (2016) who found that the commonest indication seen in $90 \%$ of children is anorectal malformation.

In contrast to Ekenze et al., (2017), AsKarpour et al., (2012) \& Hosseinpour et al., (2012) who reported that Hirschsprung's disease was more common than anorectal malformation. The patient with an imperforate anus is usually presented as an emergency with intestinal obstruction immediately after birth so urgent colostomy will be done. But in Hirschsprung's disease, some patients may respond to conservative treatment with rectal stimulation and irrigation then colostomy would be withheld. This can make high anorectal malformation the first indication for colostomy followed by Hirschsprung's disease.

The results of the present study showed that children had high rate peristomal complications (discoloration and erosion) as complication of colostomy that its severity ranged from mild to severe according to Ostomy Skin Tool (OST) that was designed to assess severity of skin in children with colostomy, this high rate of complications probably related to poor and improper care for colostomy and delayed closure of colostomy and this related to the lack of facility as colostomy bags which require hospital policy attention. Families had to buy colostomy bags which lead to increase the burden for some families with financial problems. Other families used cotton and pieces of cloths to act instead of bags while this alternative way had some problems as leakage with bad smell that increased the risk of skin complications especially in children with diarrhea.

Peristomal skin complications may evolve from fungal infections that are favored by the warm, moist climate that is found underneath the barrier flange. Cutaneous candidiasis is the most common peristomal skin infection that presents as shiny and reddened skin with pustules. An immunocompromised state or recent antibiotic use places the patient at higher risk most often; however, the infection can simply be attributed to moist peristomal skin (Behm et al., 2015).

This result was supported by Goldberg et al., (2010) who found that complications of infection, discoloration, erosion and granulation tissue occur frequently and likely are a cause of care for children with stoma and their families causing more stress and financial burden. 
Lister et al., (2010) reported that peristomal skin problems were the most common complications in children with stoma.

Results of the current study revealed that there were statistical significant differences between increase peristomal skin complications severity after one week and one month of colostomy according to domains of discoloration (area and severity) and area of erosion. The present study results are consistent with Hosseinpour et al., (2012) who reported that peristomal skin severity complications during follow up after colostomy were moderate and worsen to severe Also the current study revealed that there was no statistical significant difference between peristomal skin complications after two and three months after colostomy according to domains of Ostomy Skin Tool.

\section{Conclusion}

Based on the results of the present study, More than one half of children had mild peristomal skin complications and about one third of them had moderate ones at one week from operation. At the first month, about one half of children had moderate peristomal skin complications and two fifths of them had severe complications compared to two thirds of children that had severe complications at the second month of operation. The majority of children in third month had severe peristomal skin complications.

\section{Recommendations}

Based on the results of the current study, the following recommendations are suggested

1. Further researches should be expanded to include a larger sample, focusing on effects of peristomal skin problems on the child and family.

2. Provision of educational programs on colostomy care for mothers is suggested in order to reinforce proper practice related to peristomal skin and to increase their knowledge and practices toward colostomy care to decrease the peristomal skin complications.

3. More studies should be done on mothers burdens; emotional, financial and physical stress that affect mother care to child with colostomy and give more attentions to effect of income and parents relationship (live together, divorce or widow ) on mother when she care ostomy child.

\section{References}

1. AsKarpour S., Peyvasteh M., Changai B., \& Javaherizadeh H., (2012): Skin Bridge versus Rod Colostomy in children - comparison between complications. Pediatr Surg Int; 84(10):485-7.

2. Bakal U., Sarac M., Tartar T., \& Kazez A., (2015): Colostomy in children. FiratTipDerg /Firat Med J 2015;20(1):47-50.

3. Behm K., Larson D., \& Colibaseanu D., (2015): Intravenous immunoglobulin use in managing severe, perioperative peristomal pyoderma gangrenosum following subtotal colectomy with end ileostomy for medically refractory chronic ulcerative colitis. J Surg Case Rep. (3):1-3.

4. Bischoff A., Levitt M., \& Lawal T., (2010): Colostomy closure: how to avoid complications. Pediatr Surg Int; 26(11): 1087- 1092.

5. Bray, L., \& Sanders C., (2016): Preparing children and young people for stoma surgery. Paediatric Nursing, 18 (4). pp. 33- 37.

6. Ekenze S., Obianyo N., \& Amah C., (2017): Colostomy for large bowel anomalies in children: a case controlled study. Int J Surg; 5, n 273-277.

7. Ekwunife O., Okoli C., Modekwe V., \& Osuigwe A., (2017): Outcome of Colostomies in Children: A Review of 48 Cases at Nnamdi Azikiwe University Teaching Hospital Nnewi, Nigeria. J.Paedi.Care.Inol 1(2): 3-6.

8. Formijne J., Draaisma W., Roskott A., \& Van Overbeeke A., (2012): Early complications after stoma formation: a prospective cohort study in 100 patients with 1year follow-up. Int $\mathbf{J}$ Colorectal Dis.; 27(8):1095-1099.

9. Goldberg E., Barton S., Xanthopoulos M., Stettler N., \& Liacouras M., (2010): Bottom of Form, A Descriptive Study of Complications of Gastrostomy Tubes in Children Journal of Pediatric Nursing, 25, Issue (2 ), 72-80.

10. Harputlu D., \& Özsoy S., (2017): Turkish Reliability and Validity of the Ostomy Skin Tool. Journal of Nursing and health care 2(4): 35.

11. Hockernberry M., \& Wilson D., (2015): Wong's nursing Care of Infant and Children: the child with gastrointestinal dysfunction. 10th ed. Mosby, pp.42-1427.

12. Hosseinpour M., Fazeli A., \& Masoome A., (2012): Efficacy of Acacia Senegal stoma care in children with colostomy. European Journal for Pediatric Surgery 22(3):234-7.

13. Landmann R., (2016): Routine care of patients with an ileostomy or colostomy and management of ostomy complications. Available from: http://www.uptodate.com/contents/routine-care- 
of-patients-with-an-ileostomy-or-colostomyand-management-of-ostomy-complications. Accessed at August 18, 2018.

14. Liao C., \& Qin Y., (2014): Factors associated with stoma quality of life among stoma patients. Int. Nurs Sci; 1(2)196-201.

15. Lister J., Webster P., \& Mirza S., (2010): Colostomy complications in children. Practitioner. Feb;227(1376):229-237.

16. Martins L., Claessens I., \& Jemec G., (2013): Assessing peristomal skin changes in ostomy patients: validation of the ostomy skin tool. Br $\mathbf{J}$ Dermatol; 164 (2):330-335.

17. Nasar G., (2017): Indications \& Complications of Colostomy in Children. APMC; 11(2):110112.

18. National Cancer Institute (NCI) (2016): Ostomy clinic care. Available at: http://www.nci.nih.gov. Accessed on: $11 / 5 / 2016$.

19. Osifo O., Osaigbovo E., \& Obeta E., (2008): Colostomy in children. Indications and common problems in Benin City, Nigeria. Pak J Med Sci; 24:199-203.

20. Shauq A., (2015): Burden of Mothers' Care for Children with Colostomy at Baghdad Medical City Teaching Hospital, Iraqi National Journal of Nursing Specialties, Vol. 28 (2), 2015.

21. Simmi K., \& John R., (2018): Gastrointestinal Stoma-Ileostomy and Colostomy. EC Paediatrics SI: 36-41.

22. Wound, Ostomy Continence Nurses Society (2018): Basic ostomy skin care. Guide for patients and health care providers. http://psagconsumer.wocn.org/\#home. Accessed at October 11, 2018.

23. Zamil A., Osamah A., \& Helen S., (2018): Colostomy in Anorectal Malformation and Hirschsprung's Disease in Infants and Children. European Scientific Journal June 2018 edition Vol.14, No.18 ISSN: 1857 - 7881. 